\title{
Specialisation and training for fire-fighters driving heavy rescue vehicles: consequences for the development of operators?
}

\author{
Christine Vidal-Gomel ${ }^{\mathrm{a}}$, Catherine Delgoulet ${ }^{\mathrm{b}}$ and Déborah Gébai ${ }^{\mathrm{c}}$ \\ ${ }^{a}$ Dep. des sciences de l'éducation, CREN-Université de Nante. BP 81227, Chemin de la Cencive du Tertre; 44312 \\ Nantes Cedex 3, France \\ ${ }^{\mathrm{b}}$ Sorbonne Paris Cité, Université Paris Descartes - Laboratoire LATI (associate researcher, CREAPT). Institut de \\ psychologie. 71 avenue Edouard Vaillant; 92100 Boulogne-Billancourt, France. \\ ${ }^{c}$ Bureau d'Études en Ergonomie, ERGOnova. 78 chemin des 7 Deniers; 31200 Toulouse, France.
}

\begin{abstract}
This work was undertaken in France at the request of a local fire and rescue school in order to conduct an analysis of driving two types of heavy rescue vehicle with a view to improving training. This study took place in a context of specialisation: the drivers of these vehicles will henceforth only perform this type of task. Consequently, specific training has been designed in advance. Our study concerns the improvement of this training, taking account of the particularities of driving these vehicles in emergency situations typical to the profession of fire-fighters. The results stress first that driving of rescue vehicles in emergency situations is a multidimensional collective activity. Driving strategies identified share certain common objectives: "optimising trajectories", warn other road users, anticipate their behaviour and leave room for manoeuvre to counter and react to any unexpected behaviour. They include risks management for the potential victims of the incident and the risk of accidents during the journey. These initial results help identify certain recommendations for the training courses dealing with driving vehicles in emergency situations. They also provide a warning concerning the possible consequences of driver specialisation.
\end{abstract}

Keywords: Fire-fighters, Driving strategies, Collective activities, Training, Activity work analysis.

\section{Introduction}

The study presented here was conducted at the request of a local fire and rescue school (EDIS) or fire-fighters. The task involved analysing the activity of driving two types of vehicle - a pump wagon (PW) and an emergency support vehicle (ESV)with a view to helping to improve the driver training courses provided by the EDIS.

The study was conducted in the context of a new organisation: whereas fire-fighters with a heavy vehicle driving licence were previously authorised to drive either of the aforementioned vehicles (PW or ESV) and to participate in all rescue operations according to their rank, it was decided that driving these vehicles would henceforth be a specialised task, meaning that the drivers would only perform this type of task. Consequently, a specific training course was designed.

The specialised "driver" training concerns personnel who have already obtained the heavy vehicle

${ }^{a}$ Corresponding author: tel. (33)2 40141101 - christine.vidal-gomel@univ-nantes.fr. 
driving licence. The training focuses on the individual activity of driving: it includes an important reminder of the driving rules acquired when learning to drive and in particular explores the individual management of risks encountered when driving. The links with the content of the job are not presented.

Our study concerns the improvement of this training course by taking account of the particularities of driving vehicles in an emergency situation typical of those experienced in the fire-fighting profession. This text presents only a part of the work carried out: the results of the analysis of the activity of driving with a view to modifying the training courses.

\section{Theoretical frame}

\subsection{Driving a motor vehicle}

Driving is generally described as:

- an individual activity in which the driver travels in a motor vehicle by following a certain direction and avoiding the dangers arising due to obstacles on the road and other road users [1].

- an activity of dynamic environmental control [2] as the road environment changes, in part, independent of the action of the operator and due to the inertia of the vehicle and the behaviour of other road users. In this type of environment, awareness of the situation is decisive, with a limited awareness of the situation being associated with the risk of an accident [3]. It can be considered as the perception and understanding of a situation and of any changes which might occur in light of the action.

More recently, collective dimensions of driving have been highlighted whereby managing the risk of a collision is considered to require the interaction of several individual actions within certain time constraints [4].

This risk management necessitates the development of common references, which Darses \& Mundutéguy [4] refer to as a "cognitive environment which must be shared" by all those involved in the situation. The analysis of the activity of driving emphasises the need to anticipate the behaviour of other vehicles, for which several types of indicator can be observed during the situation. These include the position, trajectory and speed of the vehicles in close proximity as well as actions which are or are not carried out and the specific characteristics of a vehicle [4].

\subsection{Particularities of driving for fire-fighters}

To a certain extent, the emergency intervention situations particular to fire-fighters redefine the activity of driving: they involve reaching the intervention site as quickly as possible - a maximum timeframe is defined per sector of intervention according to its size and location in rural or urban areas - so that the team can handle the incident. For example, in one of the centres participating in the study, the timeframe is 7 minutes. At the same time, it involves managing the risk of accidents both for the driver and for other road users as would be the case in any normal driving situation, and also for the intervention team and for any victims of the incident.

An initial exploratory work on the driving of a VSAV (fire rescue and victim support vehicle requiring licence category B) revealed the existence of a driving strategy expressed as follows by an operator: "driving in an emergency situation means driving quickly slowly" [5]. The rules associated with this strategy were identified. For example: "in a one way street or road with several lanes, drive in the middle lane or in the middle of the street". On the one hand, this is to avoid being overtaken so that the vehicle is not impeded while on the other, it improves visibility at an intersection and enables the driver to drive on the flattest part of the road (to ensure maximum comfort for the victim being transported) and to turn the wheel suddenly if necessary while avoiding the risk of the vehicle overturning.

The role of the Chef d'Agrès ${ }^{1}$ (CA) was also highlighted to a certain extent (op. cit.). He activates the siren in coordination with the driver according to the type of situation.

The CA's anticipation strategies and the coordination with the driver's actions underline the cognitive nature of the collective actions undertaken. In particular, this involves preparing a common operating referential [6] which covers both the occurrent and distributed representation of the situation and the knowledge that this requires [7]. These strategies may require a temporal and possibly cognitive synchronisation of activities [8]. Moreover, the quality of the cooperation between the driver and the $\mathrm{CA}$ can be improved by the operators' knowledge of the other crew members, a practice referred to by Hoc [9] as meta-cooperation.

\footnotetext{
The CA may be a member of the intervention team for another mission and is not necessarily the fire-fighter with the highest rank on that particular mission.
} 
These initial results on the driving of a VSAV and the initial interpretations must nevertheless be consolidated as they refer only to the analysis of the activity of 2 fire-fighters and do not concern the driving of a heavy vehicle.

\subsection{Driving heavy vehicles}

More often than not, driving heavy vehicles is described as an individual activity whereby goods are transported over long distances. Numerous studies have explored:

- $\quad$ the layout of cabs and trailers $[10,11]$;

- the organisation and conditions of work [10, 12, 13];

- fatigue management [10, 13-15];

- the risks to the health of the operators and the risk of accidents $[12,13,16,17]$.

Having noted that heavy goods vehicles are prone to an above-average number of accidents in Europe and that the risk of accidents decreases with the level of driving experience, Falkmer \& Nordmark [18] proposed the development of simulator training. Using international survey data, they noted that the size, weight and manoeuvrability of the vehicles are risk factors. At the same time, Têtard, Quincy, Rougemoux and Vulin [19] underlined the need to factor in the principles of inertia, load and mass to prevent the risk of vehicles overturning.

The characteristics of the driving situations that we examine differ from those analysed in the aforementioned research works: fire-fighters undertake relatively short journeys (a few minutes) in emergency situations. Furthermore, the collective elements of the activity must be taken into consideration.

This collection of works on driving and heavy vehicles, together with the initial investigations conducted on the driving of a VSAV, allow us to specify the driving strategies adopted by fire-fighters both with regard to factoring in the questions of inertia, mass and load and to the collective and emergency aspects of driving. This will enable us to call into question the organisational choice of requiring heavy vehicle drivers to specialise in this task while contributing to designing their training.

\section{Methodology}

The study was conducted in two fire and rescue centres within the same local fire and rescue department (SDIS) in the Île-de-France region, one located in a rural area $(\mathrm{R})$ comprising 41 professional firefighters and 34 voluntary fire-fighters and another located in an urban area (U) comprising 45 professional fire-fighters and 19 voluntary fire-fighters.

The population which contributed to this study consisted of 12 drivers in area R and 10 in area U. The former had between 4 and 26 years' experience in the profession and between 2 and 23 years' experience of driving a heavy vehicle in intervention situations. The latter had between 5 and 28 years' experience in the profession and between 3 and 23 years' experience of driving.

The study examined two types of heavy vehicle used in the context of interventions.

The Pump Wagon (PW) weighs 8.4 tonnes empty and 15 tonnes when loaded (height: $3.5 \mathrm{~m}$, width and length: $2.5 \times 7.5 \mathrm{~m}$, surface area: $18.5 \mathrm{~m}^{2}$ ). This vehicle is used in the event of a fire. The driver and the $\mathrm{CA}$ are seated in the front with 4 fire-fighters in the rear. In centre $U$, over a period of two months in 2010 , it was used for 60 interventions while in centre $\mathrm{R}$ over the same period it was used for 80 interventions -- we selected a reference period (February to March 2010) for which we had access to all the data for both sites.

The Emergency Support Vehicle (ESV) weighs 5 tonnes empty and 8 tonnes loaded (height: $3.3 \mathrm{~m}$, width and length: $2.3 \times 5.4 \mathrm{~m}$, surface area: $12.5 \mathrm{~m}^{2}$ ). Three operators are seated in the front (the CA, the driver and a crew member). It is used in the event of road accidents to free the occupants of a vehicle. In centre $\mathrm{U}$ for the reference period, the VSR was used for 60 interventions while in centre $\mathrm{R}$, over the same period it was used for 40 interventions.

Data collection focused on departures for interventions, i.e. the journey from the fire station to the site of the accident, which is the emergency phase of the driving activity.

We conducted:

- 13 prior interviews with voluntary and profession fire-fighters. Our interview chart included general questions concerning the career path of each person, their definition of driving, the particularities of the vehicles, training, the specialisation programme, etc.;

- 44 filmed departures for an intervention. As we could not be in the vehicles, the camera was fixed to the rear view mirror, thereby filming a large part of the road environment;

- 33 post-intervention debriefings according to the availability of the operators. Our questions concerned the particularity of the in- 
tervention, the difficulties encountered during the journey and the intervention. They helped us to prepare the self-confrontations;

- 33 self-confrontations with the drivers. These took place some days after the intervention according to the availability of the operators. In particular, they concerned the analysis of "atypical situations".

These situations are "atypical" with regard to the prescribed driving rules and the dispensations concerning the Highway Code authorised for fire-fighters driving in an emergency (e.g. cutting corners and roundabouts, negotiating crossroads on the wrong side of the road, ignoring a red light). They represent "characteristic action situations": "a series of determinants which, when present simultaneously, will condition the organisation of the activity" [20]. Only some of the data has as yet been systematically analysed. We will therefore present the initial results of this work.

\section{Results}

\subsection{Driving vehicles in emergency situations: $a$ collective activity}

An operator describes a departure for an intervention: "We drop what we are doing and leave on an intervention [...] The alarm raised at $C$. comes here, the ticket corresponds to the type of problem, the address and type of vehicle required is associated with the beeper. As we are paged, we know which vehicle will be leaving and were we are to sit" (FF9R).

\subsubsection{The different phases of the intervention and the organisation of the crew}

In the 5 sequences analysed, the journey between the fire station and the intervention site can be divided into three phases, irrespective of the type of vehicle and the type of intervention: preparing the journey, driving (in town or on the open road) and parking the vehicle. A fourth phase occurs during the driving phase and/or just before the vehicle is parked: the CA allocates the tasks and explains how they must be carried out. The fire-fighters call this work phase "landing" (or "atterrissage" in French).

Depending on the situations and the crews, these different phases vary in length. For example, when the driver and the CA are used to working together and are familiar with the sector of intervention, the preparation phase is shorter (in the sequences analysed they lasted between $41 \mathrm{~s}$ and $1 \mathrm{~min} 38 \mathrm{~s}$ ).

These different phases are marked by several types of collective activity performed by the driver and the CA (in both types of vehicle) or by the driver and his crew (only in the PW).

The collective activities of the driver and the CA can be described as "collaboration" or "distributed cooperation" depending on the phase and the difficulties encountered:

- when planning the journey, preparing the intervention or driving, it is a question of distributed cooperation - the CA informs the driver of the route - or collaboration when one of them is not sufficiently familiar with the route. For example: "[...] you communicate with your "chef" and then sometimes you quickly look at the map to tell him where we are coming from. It works both ways; the "chef" can also correct the driver who thought he could take a certain route but was wrong" (FF9R).

- when driving, distributed cooperation activities can be seen in the use of the siren (we will explain this point below) and in the visual controls performed by the CA. For example, the driver overtakes a vehicle when there is a vehicle coming the other way "[...] Here, the role of the chef d'agrès is very important because the other vehicle is in my blind spot and I can't see it." (FF3R).

Other types of collective activity can be identified involving the driver and the crew members:

- When driving, the driver takes account of his crew's activity in the rear: "if the guys are preparing for the intervention, getting dressed, there's no point in throwing them around [...] so I drive less quickly at the start to give them the time to get dressed" (FF9R).

- During the "landing" phase, he is attentive to the orders given to the crew members by the CA. This will allow him to understand which crew member to help and how to help as well as anticipating his needs: "Knowing how to supply, [...] opening the compartments according to the crew's needs. [...] Knowing where the water outlets are, if

\footnotetext{
${ }^{2}$ According to Rogalski [21]: a) in "collaboration", the actors share the same prescribed task; b) in "distributed cooperation", the immediate aims of each operator differ, but contribute to a common task.
} 
the fire is in an apartment, if it is at a certain height, the crew will quickly need a ladder which is on the roof so you quickly have to remove the reels to access the ladders. If it's a harmless bin fire or a ground level fire, you know that only the hose will be required." (FF12R).

\subsubsection{Using the siren}

The siren can be activated by the driver or the $\mathrm{CA}^{3}$. In the sequences that we filmed, the CA generally assumed responsibility for the siren. An operator explained the need for the CA to anticipate and to take the characteristics of the different situations into account:

"[...] chef d'agrès must anticipate the driving actions as he activates the siren. [...] He calls on his experience; if we come to a roundabout which is clear, he will maybe activate the siren a little later, if he has poor visibility he'll activate it much earlier" (FF3R).

These different uses of the sirens by the CA and his anticipation require a familiarity with the driver's style of driving and the driving constraints. They rely on the temporal synchronisation of activities due to the temporal dependence of the actions to be carried out in relation to the dynamics of the process (warning other road users in good time of the arrival of the emergency vehicle).

We observed certain rare situations in which the driver activated the siren: "When the chef d'agrès is too busy, I use it myself' (FF10R).

- These comments, and those noted previously, demonstrate the inclusion of the other crew member's constraints. They can be seen as an indicator of meta-cooperation [9].

\subsection{Drivers' strategies in emergency situations}

Here, we present two of the strategies identified: driving between lanes of traffic with the ESV and negotiating a roundabout with the $\mathrm{PW}$.

\subsubsection{Driving between lanes of traffic with the Emergency Support Vehicle}

In order to drive between lanes of traffic, it is important to warn other drivers so that they can make space. Fire-fighters adopt a specific strategy by using the siren well before arriving behind other vehicles.

\footnotetext{
${ }^{3}$ The prescriptions and jurisprudence are not clear on this point. Furthermore, the design of the dashboards enables the CA to activate it easily.
}

Once they are behind another vehicle, the siren is stopped and the means of communication (siren, headlights) are only used to transmit specific information to the other users.

The use of the siren may cause other road users to "panic", thereby increasing the risk of accidents, or to stop without pulling over and making space. Furthermore, it is not a question of waiting for the road in front to be free, "you have to impose yourself', while leaving some room for manoeuvre; the behaviour of other drivers can be unpredictable: "There are always some people who don't understand, who look in their rear view mirrors when we are already beside them." Several indicators of the behaviour of other road users were expressed during the selfconfrontations: "movements of the head" (mostly for motorcyclists), "the behaviour of the wheels", how often the brake lights come on: "they are flashing."

\subsubsection{Negotiating a roundabout with the Pump Wagon}

The strategy is aimed at negotiating a roundabout on the inside in order to optimise the trajectory and avoid tipping while maintaining a good speed. This strategy also avoids any ambiguity in communication with the other road users as they tend to pull in to the right.

The drivers' strategy contradicts the rule stipulated and defended by trainers. A heavy vehicle should take a roundabout on the outside to avoid presenting a problem for other traffic when exiting the roundabout. According to one of the trainers, this "allows the driver to close the angle to other others and makes it easier to exit the roundabout." Taking a roundabout on the outside would also help to avoid the tipping effect. Another trainer explains: "roundabouts are raised in the middle so by taking the outside lane, you avoid any tipping. Otherwise, if you are forced to brake suddenly, there is a risk of overturning."

Paradoxically, the drivers' strategy takes account of the risks indicated by the trainers but integrates the others road users' tendency to make space by moving to the outside of the roundabout. They also take account of tipping by cutting across the roundabout. For the drivers, it is a question of managing several types of risk simultaneously: the vehicle overturning, being impeded by or even colliding with another vehicle and, in the case of the PW, causing an uncomfortable journey or injuring crew members who could be thrown about in the rear. Not taking account of these risks in their activity could lead to the ultimate risk: 
non-assistance of the victim who is the very reason for the emergency intervention.

\section{Conclusion}

The driving of rescue vehicles in emergency situations by fire-fighters is a multidimensional collective activity, which was not identified either by operators themselves and their hierarchy. It is an activity involving driver-CA complementarity and, in the case of a PW, it is an activity, which concerns the crewmembers being transported. It is also an activity, which takes place in the shared environment of the road. In that way, the working organization stood out of the team activity: this is a form of "organizational work" [22]. Paradoxically, the hierarchy ignored this emergent working organization and chose the logic of drivers' specialization.

The two driving strategies identified share certain common objectives: adopting the straightest trajectory possible, in order to minimise tipping and the risk of overturning the vehicle, and not stopping as it is essential to arrive at the intervention site as quickly as possible to limit the material and physical damage resulting from the incident while also minimising the driving risks, in other words "driving quickly slowly" as we have already seen. With this in mind, it is necessary to "optimise trajectories", warn other road users, anticipate their behaviour and leave room for manoeuvre to counter and react to any unexpected behaviour.

These collective strategies oriented towards the intervention team therefore include risk management activities: risks for the potential victims of the incident and the risk of accidents during the journey (overturning the vehicle or a collision with other road users), the consequences of which concern the driver, his fellow crew members, other road users and the victims of the incident.

These initial results help identify certain recommendations for the training courses dealing with driving vehicles in emergency situations by demonstrating the importance of taking driver strategies into account in both their individual and collective dimensions.

These results also provide a warning concerning the possible consequences of driver specialisation. In the long term, the CA will no longer have systematically driven rescue vehicles in emergency situations and his contribution to managing risks by using the siren and checking the road situation will be affected accordingly. We might hypothesise that creating a common operating referential with the driver will, in the future, be based solely on their shared experience, making initial collaboration all the more difficult. Moreover, the choice of driver specialisation will endanger the drivers' contribution to intervention tasks. As they will no longer participate in these activities, they will encounter greater difficulty in interpreting the orders given by the CA during the "landing" phase with a view to anticipating the needs of the other crewmembers and helping them, unless these two points are included in the training. This creates obstacles for sustainable development of operators' individual and collective skills.

Finally, specialisation could lead to new objectives being included in the training, which would then be oriented towards teaching collective activities in order to help the intervention teams identify and manage the different risks encountered when driving rescue vehicles in emergency situations.

\section{Acknowledgement}

We wish to thank the university Paris 8 - Vincennes - Saint-Denis for his support to this communication.

\section{References}

[1] Neboit M, Simulation et apprentissage de la conduite automobile. Le travail humain. 1978; 41: 239-249.

[2] Hoc JM, Supervision et contrôle de processus. La cognition en situation dynamique. Grenoble (F): PUG; 1996.

[3] Kaber D.B., Endsley M.R. Team situation awareness for process control. Safety and performance, Process Safety Progress. 1998; 17: 43-51.

[4] Munduteguy C, Darses F. Perception et anticipation du comportement d'autrui en situation simulée de conduite automobile. Le travail humain. 2007; 70: 1-32.

[5] Bensimon S. Analyse de la conduite en situation d'intervention urgente: le cas des sapeurs pompier, Mémoire de Master 1 de psychologie (mention: Ergonomie cognitive et TIC). Saint-Denis (F): Université Paris 8, 2009.

[6] de Terssac G., Chabaud C. Référentiel opératif commun et fiabilité. In: Leplat J, de Terssac G, editors. Les Facteurs humains de la fiabilité dans les systèmes complexes. Toulouse $(F)$ : Octarès editions; 1990. p. 111-139.

[7] Giboin A. La construction de référentiels opératifs communs dans le travail coopératif. In: Hoc JM, Darses F, editors. Psychologie ergonomique: tendances actuelles. Paris (F): PUF; 2004. p. 119-139.

[8] Rogalski J. Le travail collaboratif dans la réalisation des tâches collectives. In: Lautrey J, Richard JF, editors. L'intelligence. Paris (F): Lavoisier; 2005. p. 75-87. 
[9] Hoc JM. Vers une coopération homme-machine en situation dynamique. In: Falzon P, editor. Ergonomie. Paris (F): PUF; 2004. p. $269-283$

[10] Oron-Gilad T., Shinar D. Driver fatigue among military truck driver. Transportation research part F. 2001; 3: 195-209.

[11] Patenaude S, Marchand D, Samperi S, Bélanger M. The effect of the descent technique and truck cabin layout on the landing impact forces. Applied ergonomics. 2001; 32: 573-582.

[12] Hamelin P. Les conditions de travail des conducteurs routiers et la sécurité routière. Le travail humain. 1981; 44.

[13] Germain C, Blanchet V. La fatigue des routiers et ses conséquences en termes de sécurité. Recherche Transport Sécurité. 1995; 49. Paris (F): INRETS.

[14] McDonald N. Fatigue, safety and the truck driver. London (UK): Taylor \& Francis; 1984

[15] Feyer AM, Williamson AM. The influence of operational conditions on driver fatigue in the long distance road transport industry in Australia, International Journal of industrial ergonomics. $1995 ; 15$ : 229-235.
[16] Hamelin P. Lorry driver's time habits in work and their involvement in traffic accidents. Ergonomics. 1987; 30: 1323-1333.

[17] Stoohs RA, Guilleminault C, Itoi A, Dement WC. Traffic accidents in commercial long-haul truck drivers: the influence of sleep-disordered breathing and obesity. Sleep. 1994; 17: 619-623.

[18] Falkmer T, Nordmark S. Truck simulator feasibility study, European report "Trainer"-GRD1-1999-10024. UE; 2002. Avilable form: http://www.cieca.be

[19] Têtard C, Quincy R, Rougemoux JP, Vulin D. L'insécurité des poids lourds dans les longues descentes. Rapport INRETS. 1992; 152. Paris (F): INRETS.

[20] Daniellou F. Le statut de la pratique et des connaissances dans l'intégration ergonomique de conception. Thèse d'habilitation à diriger des recherches. Toulouse $(\mathrm{F})$ : Université de Toulouse - Le Mirail; 1992.

[21] Rogalski, J. Formation aux activités collectives. Le travail humain. 1994; 54: 367-386

[22] de Terssac G. Le travail: une aventure collective. Recueil de textes. Toulouse $(\mathrm{F})$ : Octarès; 2002 